\title{
UTJECAJ OBORINA NA PRINOS SJEMENA OZIMOG STOČNOG GRAŠKA
}

\author{
S. POPOVIĆ, Marijana TUCAK, T. ČUPIĆ \\ Poljoprivredni institut Osijek \\ Agricultural Institute Osijek
}

\begin{abstract}
SAŽETAK
Ozimi stočni grašak (Pisum arvense L.) sve se više sije u Hrvatskoj i njenom okruženju za proizvodnju kvalitetne voluminozne krme. Sjemenska proizvodnja ozimog stočnog graška vrlo je složena, a time i neizvjesna najviše radi same građe i visine stabljike. Stabljika na kraju vegetacije je visine između 1,5 i 2 metra i pod težinom mahuna poliježe što znatno otežava žetvu i povećava gubitke sjemena. U poljoprivrednoj proizvodnji ostvarivanje većeg ili manjeg prinosa, osim genetike sijane sorte ili hibrida, najčešće se povezuje s okolinskim uvjetima tijekom vegetacije, a prije svih $\mathrm{s}$ količinom oborina.

$\mathrm{U}$ radu je napravljena analiza sjemenske proizvodnje ozimog stočnog graška, sorte Osječki zeleni na površinama Poljoprivrednog instituta Osijek za devetogodišnje razdoblje (2004.-2012. godina) i klimatskih prilika te je utvrđeno veliko variranje kako u prinosu, klijavosti i masi 1000 sjemenki tako i u količini oborina tijekom vegetacijskog perioda ozimog graška u analiziranim godinama. Korelacijska analiza po Pearsonu pokazala je nepostojanje veze između prinosa, klijavosti i mase 1000 sjemena te analiziranih parametara $\mathrm{i}$ ukupne količine oborina $\mathrm{u}$ vegetacijskom periodu graška, ali niti s količinom oborina po mjesecima, iz čega se može zaključiti da su promatrani parametri pod znatnim utjecajem drugih čimbenika.
\end{abstract}

Ključne riječi: ozimi stočni grašak, oborine, prinos sjemena

\section{UVOD}

Ozimi stočni grašak (Pisum arvense L.) zauzima sve veće površine u Republici Hrvatskoj i njenom okruženju prvenstveno zbog visokog prinosa zelene mase bogate bjelančevinama, niskih financijskih ulaganja i malih tehnoloških zahtjeva u proizvodnji voluminozne krme (Čupić i sur., 2013). Druga ne manje značajna karakteristika proizvodnje ozimog stočnog graška je rano napuštanje površina (tijekom svibnja) što 
otvara mogućnost druge sjetve i cjelogodišnje pokrovnosti obradivih površina, a time i maksimalno korištenje oranica. Također, ozimi stočni grašak ostavlja značajne količine organske tvari i dušika u tlu za narednu kulturu. Krma ozimog stočnog graška je gotovo „ekološki“ proizvedena jer nema potrebe za korištenjem pesticida u proizvodnji, a i uporaba mineralnih gnojiva se svodi na najmanju mjeru. Potražnja sjemena ozimog stočnog graška značajno je povećana u zadnjih desetak godina kada je veliki broj obiteljskih gospodarstava uložio značajna sredstva u izgradnju farmi za proizvodnju mlijeka. Ishrana muznih krava, najčešće sjenažom ozimog graška, pokazala je odlične rezultate u povećanju produkcije i kvalitete mlijeka koja se ogleda u većem sadržaju mliječne masti (Čupić i sur., 2010).

Podataka o zasijanim površinama ozimog stočnog graška nema u službenom statističkom ljetopisu RH ali postoji podatak da je 2008. godine zasijano 2.308 ha jednogodišnje zelene krme, a najvjerojatnije se većina ovih zasijanih površina odnosi na ozimi grašak. Za sjetvu površina pod ozimim stočnim graškom, koji je u ekspanziji, treba proizvesti dovoljne količine sjemena. Proizvodnja sjemena ozimog graška je složenija i neizvijesnija od proizvodnje voluminozne krme što potvrđuju i radovi autora Tan-a i sur. (2012), Turk-a i sur. (2011), Takeli-a i Ates-a (2003). Teškoće u sjemenskoj proizvodnji ozimog stočnog graška uvjetovane su prije svega visinom biljaka i građom stabljike. Biljke sijane sorte (Osječki zeleni) su u vrijeme žetve prosječne visine oko $190 \mathrm{~cm}$ te pod težinom mahuna poliježu, što značajno otežava žetvu i povećava gubitke sjemena. Visina biljaka i debljina stabljike su morfološka svojstva, genetski nasljedna, ovisna o sijanoj sorti i okolinskim čimbenicima. U proizvodnji sjemena ozimog stočnog graška sorte Osječki zeleni na površinama Poljoprivrednog instituta Osijek analiziran je utjecaj oborina na prinos sjemena za razdoblje od 2004. do 2012. godine.

\section{MATERIJAL I METODE}

Proizvodnja sjemena ozimog stočnog graška sorte Osječki zeleni u razdoblju od 2004. do 2012. godine provedena je na površinama Poljoprivrednog instituta Osijek. U svim proizvodnim godinama sijano je $120 \mathrm{~kg} \mathrm{ha}^{-1}$ graška i $50 \mathrm{~kg} \mathrm{ha}^{-1}$ pšenice sorte Žitarka. Ova sorta ima relativno nisku čvrstu stabljiku, a sije se s ciljem da ublaži potpuno polijeganje usjeva graška te olakša žetvu usjeva. U svim analiziranim godinama smjesa ozimog grašaka i pšenice sijana je kombiniranom sijačicom za žitarice (međuredni razmak $13 \mathrm{~cm}$ ) koja ima roto-frezu, te je obavljena $\mathrm{u}$ jednom prohodu direktno na oranje u terminima od 15. listopada do 01. studenog. Sjetvene površine Poljoprivrednog instituta Osijek definirane su kao eutrični kambisol, odnosno smeđe tlo, blago kisele do neutralne reakcije ( $\mathrm{pH} \mathrm{u} \mathrm{KCl-u} \mathrm{6,4-7,0)} \mathrm{s} \mathrm{preko} 30 \mathrm{mg} / 100 \mathrm{~g}$ tla $\mathrm{P}_{2} \mathrm{O}_{5}$ i $\mathrm{K}_{2} \mathrm{O}$ te s oko $2 \%$ humusa. Na površinama za proizvodnju sjemena ozimog stočnog graška prije sjetve dodano je $200 \mathrm{~kg} \mathrm{ha}^{-1}$ mineralnog gnojiva N:P:K kombinacije 7:20:30 i 50-100 $\mathrm{kg} \mathrm{ha}^{-1}$ UREA-e. Žetva je obavljena kombajnom u terminima od 25. 
S. Popović i sur.: Utjecaj oborina na prinos sjemena ozimog stočnog graška

lipnja do 10. srpnja, ovisno o klimatskim prilikama, odnosno kada je vlaga zrna bila ispod $13 \%$. Nakon žetve vaganjem je utvrđena količina naturalnog sjemena (smjesa graška i pšenice), a nakon dorade masa dorađenog sjemena te prinos čistog sjemena ozimog stočnog graška po hektaru. Iz uzorka čistoga sjemena određena je masa 1000 zrna, energija klijanja i klijavost. Dorada sjemena kao i analize kvalitete sjemena provedena su u pogonu za doradu i laboratoriju Odjela za sjemenarstvo Poljoprivrednog instituta Osijek.

\section{KLIMATSKE PRILIKE}

Klimatske prilike, srednje mjesečne temperature zraka i količine oborina u vegetaciji ozimog stočnog graška te višegodišnji prosjek (1971.-2000.) prikazani su u Tablicama 1 i 2 .

Tablica 1. Srednja mjesečna temperatura zraka za Osijek tijekom vegetacije $\left({ }^{0} \mathrm{C}\right)$

Table 1 Mean monthly temperature for Osijek during the growing season $\left({ }^{0} \mathrm{C}\right)$

\begin{tabular}{lcccccccccc}
\hline $\begin{array}{c}\text { Mjesec/ } \\
\text { Month }\end{array}$ & \multicolumn{1}{c}{ G o d i n a / Ye ar } & & \multicolumn{1}{c}{$\begin{array}{c}\text { Prosjek/ } \\
\text { Average } \\
1971 .-2000 .\end{array}$} \\
\cline { 2 - 10 } & 2004. & 2005. & 2006. & 2007. & 2008. & 2009. & 2010. & 2011. & 2012. & 1971.4 \\
\hline $\begin{array}{l}\text { Ožujak/ } \\
\text { March }\end{array}$ & 5,9 & 4,1 & 5,4 & 8,5 & 7,5 & 6,8 & 6,8 & 6,4 & 6,2 & 6,4 \\
$\begin{array}{l}\text { Travanj/ } \\
\text { April }\end{array}$ & 12,0 & 11,5 & 12,7 & 13,3 & 12,5 & 14,6 & 12,4 & 13,2 & 11,5 & 11,2 \\
$\begin{array}{l}\text { Svibanj/ } \\
\text { May }\end{array}$ & 15,4 & 17,0 & 16,2 & 18,3 & 18,1 & 18,3 & 16,5 & 16,7 & 16,5 & 16.7 \\
$\begin{array}{l}\text { Lipanj/ } \\
\text { June }\end{array}$ & 19,8 & 19,5 & 20,1 & 22,3 & 21,5 & 19,2 & 20,4 & 20,7 & 19,8 & 19,6 \\
\hline
\end{tabular}

Tablica 2. Mjesečna količina oborina tijekom vegetacije (mm)

Table 2 Monthly rainfalls during the growing season ( $\mathrm{mm}$ )

\begin{tabular}{cccccc}
\hline $\begin{array}{c}\text { Godina/ } \\
\text { Year }\end{array}$ & $\begin{array}{c}\text { Ožujak/ } \\
\text { March }\end{array}$ & $\begin{array}{c}\text { Travanj/ } \\
\text { April }\end{array}$ & $\begin{array}{c}\text { Svibanj/ } \\
\text { May }\end{array}$ & $\begin{array}{c}\text { Lipanj/ } \\
\text { June }\end{array}$ & $\begin{array}{c}\text { Ukupno/ } \\
\text { Total }\end{array}$ \\
\hline 2004. & 29,6 & 122,0 & 63,3 & 88,4 & 303,3 \\
2005. & 54,0 & 55,3 & 50,5 & 110,2 & 270,0 \\
2006. & 52,5 & 86,8 & 78,6 & 78,0 & 295,9 \\
2007. & 76,0 & 2,9 & 56,1 & 33,3 & 168,3 \\
2008. & 82,4 & 48,8 & 66,9 & 76,3 & 274,4 \\
2009. & 26,5 & 18,7 & 39,4 & 62,8 & 147,4 \\
2010. & 22,2 & 71,1 & 120,8 & 234,0 & 448,1 \\
2011. & 37,2 & 19.9 & 80,1 & 50,2 & 187,4 \\
2012. & 45,0 & 58,8 & 69,1 & 83,0 & 255,9 \\
Prosjek/Average & 40,5 & 51,0 & 59,2 & 82,0 & 232,7 \\
1971.-2000. & & & & & \\
\hline
\end{tabular}


S. Popović i sur.: Utjecaj oborina na prinos sjemena ozimog stočnog graška

\section{REZULTATI I RASPRAVA}

Promatrajući srednju mjesečnu temperaturu (Tablica 1) vegetacijskog perioda analiziranih godina proizvodnje sjemena ozimog stočnog graška mogu se uočiti znatna odstupanja od višegodišnjeg prosjeka. U većini mjeseci i godina temperature su bile nešto više od višegodišnjeg prosjeka što nije išlo u prilog rasta i razvoja ozimog graška koji bolje rezultate daje u hladnijim i vlažnijim okolinama. Odstupanje temperatura zraka kretalo se u granicama od $+/-2^{\circ} \mathrm{C}$. Veća odstupanja od višegodišnjeg prosjeka, a naročito između proizvodnih godina uočavaju se kod mjesečnih količina oborina (Tablica 2). U vegetacijskom periodu (ožujak-lipanj) količina oborina po godinama varirala je od 147,4 do 448,1 mm, dok je višegodišnji prosjek 232,7 mm. Još veća odstupanja od višegodišnjeg prosjeka događala su se po mjesecima te je bilo za pretpostaviti da se veliko variranje prinosa sjemena ozimog stočnog graška dogodilo zbog razlika u količini oborina (Tablica 3). Za provjeru pretpostavke napravljena je korelacijska analiza po Pearsonu gdje je ispitan odnos između prinosa zrna, mase 1000 zrna i klijavosti sjemena ozimog stočnog graška sorte Osječki zeleni i količine oborina po analiziranim godinama i mjesecima.

Tablica 3. Proizvodnja sjemena ozimog stočnog graška na Poljoprivrednom institutu Osijek Table 3 Production of pea seeds at the Agricultural Institute Osijek

\begin{tabular}{|c|c|c|c|c|c|c|c|}
\hline $\begin{array}{l}\text { Godina } \\
\text { /Year }\end{array}$ & $\begin{array}{c}\text { Zasijano/ } \\
\text { Sown } \\
\text { ha }\end{array}$ & $\begin{array}{l}\text { Ukupno } \\
\text { naturalno/ } \\
\text { In total } \\
\text { subsistent } \\
\mathrm{kg}\end{array}$ & $\begin{array}{c}\text { Ukupno } \\
\text { dorađeno } \\
\text { graška / } \\
\text { Total } \\
\text { processed } \\
\text { pea } \\
\text { kg }\end{array}$ & $\begin{array}{c}\text { Iskorištenje / } \\
\text { Utility } \\
\%\end{array}$ & $\begin{array}{c}\text { Klijavost } \\
\text { / Germin. } \\
\%\end{array}$ & $\begin{array}{c}\text { Masa } 1000 \\
\text { zrna / } \\
\text { 1000 Seed } \\
\text { weight g }\end{array}$ & $\begin{array}{c}\text { Prinos / } \\
\text { Yield } \\
\mathrm{kg} \mathrm{ha}^{-1}\end{array}$ \\
\hline 2004. & 8 & 10.500 & 9.170 & 87,3 & 91 & 105 & 1.146 \\
\hline 2005 . & 9 & 11.715 & 10.280 & 87,7 & 85 & 116 & 1.142 \\
\hline 2006. & 10 & 21.520 & 18.215 & 84,6 & 95 & 104 & 1.821 \\
\hline 2007. & 16 & 31.200 & 23.980 & 76,9 & 86 & 106 & 1.498 \\
\hline 2008. & 15 & 37.980 & 30.750 & 80,0 & 84 & 89 & 2.050 \\
\hline 2009. & 20 & 45.800 & 27.960 & 61,0 & 83 & 117 & 1.398 \\
\hline 2010 . & 15 & 31.500 & 24.300 & 77,1 & 93 & 91 & 1.600 \\
\hline 2011. & 23 & 65.840 & 56.470 & 85,8 & 91 & 111 & 2.455 \\
\hline 2012. & 12 & 36.660 & 29.040 & 86,3 & 83 & 108 & 2.420 \\
\hline
\end{tabular}


Iz Tablice 3 vidljivo je da se zasijana površina za proizvodnju viših kategorija sjemena ozimog stočnog graška kretala od 8-23 hektara uz stalni trend povećanja. U 2012. godini bilo je zasijano 12 ha sorte Osječki zeleni, ali i 10 ha nove vrlo rane sorte vitičastog tipa lista pod imenom Letin. Nova sorta Letin zbog vitičastog tipa lista $i$ međusobne povezanosti biljaka nije sklona polijeganju te se može sijati bez nosača, kako u proizvodnji voluminozne krme tako i u sjemenskoj proizvodnji. Prinos zrna ozimog stočnog graška značajno je varirao u promatranom devetogodišnjem razdoblju od 1.142 do $2.455 \mathrm{~kg} \mathrm{ha}^{-1}$. Slične prinose dobili su Takeli i Ates (2003) ispitujući prinos sjemena pet linija ozimog stočnog graška kroz tri godine. U njihovim istraživanjima prinos sjemena kretao se od 1.602 do $2.590 \mathrm{~kg} \mathrm{ha}^{-1}$ uz visinu biljaka između 107 i $124 \mathrm{~cm}$ i količinu oborina od 314 do $513 \mathrm{~mm}$ za cijelu vegetaciju (studenilistopad). Muehlbauer (1998) navodi da je prinos sjemena ozimog krmnog graška dvije sorte u prosjeku iznosio $2.071 \mathrm{~kg} \mathrm{ha}^{-1}$ u 1994., a u 1995 . godini $3.327 \mathrm{~kg} \mathrm{ha}^{-1}$. Značajno manje prinose sjemena dobili su Hatam i Amanullah (2002) koji su ispitivali 13 genotipova ozimog graška visine od 115 do $190 \mathrm{~cm} \mathrm{~s} \mathrm{kojima} \mathrm{su} \mathrm{ostvarili}$ prinose od 49 do $1000 \mathrm{~kg} \mathrm{ha}^{-1}$, s tim da je genotip čija je visina bila $190 \mathrm{~cm}$ ostvario prinos sjemena od svega $67 \mathrm{~kg} \mathrm{ha}^{-1}$. Iskorištenje u doradi pokazuje postotak čistog dorađenog sjemena graška u odnosu na proizvedenu naturalnu količinu koja se sastojala od sjemena graška, zrna pšenice, mehaničkih nečistoća i drugih primjesa. U procesu dorade sjemena graška sve primjese i nečistoće moguće je razdvojiti te se stvarani neiskoristivi otpad kretao od 0,7 do $12,8 \%$, a iz naturalnog sjemena izdvojeno je od 5,6 do $26,2 \%$ iskoristivog otpada. Iskoristivi otpad većinom čini zrno pšenice i polomljena sjemena graška. Zrno pšenice u daljnjem procesu dorade može se potpuno izdvojiti što znači da se uz sjeme graška proizvelo i približno $100-500 \mathrm{~kg} \mathrm{ha}^{-1}$ pšenice (Tablica 4).

Tablica 4. Gubitci tijekom dorade ozimog stočnog graška (Osječki zeleni)

Table 4 Losses during processing pea (Osječki zeleni)

\begin{tabular}{ccccc}
\hline $\begin{array}{c}\text { Godina/ } \\
\text { Year }\end{array}$ & \multicolumn{2}{c}{ Iskoristiv otpad/ } & \multicolumn{2}{c}{ Neiskoristiv/Unusable Waste } \\
& $\mathrm{kg}$ & $\%$ & $\mathrm{~kg}$ & $\%$ \\
\hline 2004. & 590 & 5,6 & 740 & 7,1 \\
2005. & 1.360 & 11,6 & 76 & 0,7 \\
2006. & 2.210 & 10,3 & 1.095 & 5,1 \\
2007. & 5.400 & 17,3 & 1.820 & 5,8 \\
2008. & 4.750 & 12,5 & 2.480 & 7,5 \\
2009. & 11.980 & 26,2 & 5.860 & 12,8 \\
2010. & 5.740 & 18,2 & 1.460 & 9,6 \\
2011. & 7.015 & 10,5 & 2.355 & 3,7 \\
2012. & 3.400 & 10.1 & 1.220 & 3,6 \\
\hline
\end{tabular}


Da ozimi stočni grašak za proizvodnju sjemena treba sijati kao združeni usjev s žitaricom utvrdili su Murrayi Swensen (1985) koji su dobili povećanje prinosa zrna graška od $27 \%$, sjetvom $25 \%$ pšenice s graškom u odnosu na sjetvu čistog graška. Analizirajući utjecaj oborina na prinos sjemena, klijavost i masu 1000 zrna ozimog stočnog graška, sorte Osječki zeleni u razdoblju od 2004. do 2012. godine, utvrđeno je da prinos sjemena i klijavost nisu bili u korelacijskom odnosu s količinom oborina, ali da je količina oborina negativno utjecala na masu 1000 zrna (Tablica 5).

Tablica 5. Pearsonova korelacija

Table 5 Pearson Correlation

\begin{tabular}{lccc}
\hline & $\begin{array}{c}\text { Prinos/ } \\
\text { Yield }\end{array}$ & $\begin{array}{c}\text { Masa 1000 zrna/ } \\
\text { 1000 seed weight }\end{array}$ & $\begin{array}{c}\text { Klijavost/ } \\
\text { Germination }\end{array}$ \\
\hline $\begin{array}{l}\text { Oborine/ } \\
\text { Precipitation }\end{array}$ & $-0,12$ & $-0,66^{*}$ & 0,53 \\
$\begin{array}{l}\text { Prinos/ } \\
\text { Yield }\end{array}$ & & $-0,20$ & $-0,02$ \\
Masa 1000 zrna/ & & $-0,30$ \\
1000 seed weight & & & \\
\hline
\end{tabular}

*Korelacija je značajna na razini $0,05 / *$ Correlation is significant at the 0,05 level

Također utvrđeno je da prinos sjemena, klijavost i masa 1000 zrna ozimog stočnog graška nisu bili u korelacijskoj vezi s količinom oborina po mjesecima. Razlike u prinosu sjemena po analiziranim godinama proizvodnje vjerojatno su posljedica polegnutosti usjeva i nedovoljno kvalitetnih tehničkih rješenja u procesu žetve. Žetva jako polegnutog usjeva tehnički je vrlo složena, posebno zbog toga što su polegnute biljke približno $2 \mathrm{~m}$ dužine. Ukoliko se žetva provodi na način da kosa kombajna ide ispod usjeva dolazi do čupanja, otresanja biljaka, raspucavanja mahuna i velikih gubitaka sjemena. Na jako polegnuti usjev kombajn mora ići u pravcu polijeganja, a tada kosa zahvaća samo manji dio biljke i veliki broj mahuna ostaje na polju ne pokošen. I u ovom slučaju gubitci sjemena su veliki. Stoga je uloga žitarice, posebno u sjemenskoj proizvodnji ozimog graška, vrlo važna jer žitarica ne dopušta da grašak potpuno polegne te omogućuje lakšu i uspješniju žetvu s manje gubitaka sjemena.

\section{ZAKLJUČCI}

Provedena analiza utjecaja količine oborina na prinos sjemena, klijavost i masu 1000 zrna kroz devetogodišnje razdoblje proizvodnje ozimog stočnog graška sorte Osječki zeleni na Poljoprivrednom institutu Osijek pokazala je da veliko variranje 
prinosa i klijavost sjemena nisu bili u korelacijskoj vezi s količinom oborina. Na razlike u prinosu sjemena ozimog graška vjerojatno je utjecao stupanj polegnutosti usjeva te $s$ tim u vezi nedovoljno kvalitetna tehnička i tehnološka rješenja u procesu žetve. Masa 1000 zrna i količina oborina bile su u značajnom negativnom korelacijskom odnosu.

\section{PRECIPITATION INFLUENCE ON THE YIELD OF PEA SEEDS}

\section{SUMMARY}

Forage pea (Pisum arvense L.), is increasingly being planted in Croatia and its environment to produce high-quality forage. Seed production of pea is very complex process, mostly because of the plant structure and plant height. Plant height at the end of the growing season varied between 1.5 to 2 meters due to which lodging can occur because of the weight of the pod, which significantly complicates harvest. In agricultural production the yield is under the influence of plant genetic potential and environmental factors especially of the amount of precipitation during the growing season.

In the work an analysis of seed pea production of variety Osječki zeleni at the Agricultural Institute Osijek depending of climatic conditions for the nine year period (2004-2012) were made. Analyses showed the large fluctuations in sin yield, germination and 1000 seed weight and oscillations in the amount of precipitation during the growing period of winter peas in the analysed years. Pearson correlation analysis showed a lack of relation between yield, germination and 1000 seed weight. There was no correlation observed between tested parameters and the total amount of precipitation during the growing period, and between analysed parameters and the amount of precipitation per month, from which it can be concluded that the observed parameters were substantially influenced by other environmental factors.

Key words: forage pea, seeds production, precipitation

\section{LITERATURA - REFERENCES}

1. Čupić, T., Popović, S., Gantner, R., Tucak, M., Sudar, R. (2010): Nutritive value assesment of whole semi-leafless plant of forage type pea in milk production. Mljekarstvo 60 (4):266-272.

2. Čupić, T., Popović, S., Tucak, M.,Jukić, G., Rukavina I. (2029): Impact of the semy-leafless field pea on dry matter yield. Journal of central European 14 (1):102-106.

3. Hatam, M., Amanullah, J. (2002): Graim Yield Potential of Field Pea (Pisum arvense L.) Gerplasm. Asian journal of Plant Sciences 1 (2):180-181. 
4. Muehlbauer, F. J. (1998): Legume Breeder, U.S. Department of Agriculture, Agricultural Research Service and The Department of Crop and Soil Sciences, Washington State University, Pullman, Washington USA 99164-6434.

5. Murray, G. A., Swensen, J.B. (1985): Peas Intercropped with Winter Cereals. Agronomy Journal 77 (6):913-916.

6. Takeli, A. S., Ates, E. (2003): Yield and its Components in Field Pea (Pisum arvense L.) Lines. Journal of Central European Agriculture 4 (4):313-317.

7. Tan, M., Koc, A., Dumlu Gul, Z. (2012): Morphological characteristic and seed yield of East Anatolian Local Forage Pea (Pisum sativum ssp. arvense L.) ecotypes. Turkish Journal of Field Crops 17 (1):24-30.

8. Türk, M., Albayrak, S., Yüksel, O. (2011): Effect of seeding rate on forage yields and Quality in Pea Cultivars of differing Leaf Types. Turkish Journal of Field Crops 16 (2):137-141.

Adresa autora - Author's address:

Dr. sc. Svetislav Popović

Dr. sc. Marijana Tucak

Dr. sc. Tihomir Čupić

Poljoprivredni institut Osijek

Južno predgrađe 17, HR - 31000 Osijek

E-mail: svetislav.popovic@poljinos.hr
Primljeno-Received:

09. 04. 2013. 